\title{
Sustaining Industry Leadership Through Innovation Strategy Archetypes
}

\author{
Theuns G. Pelser, North-West University, South Africa
}

\begin{abstract}
The ability to innovate and exploit innovations globally in a rapid and efficient manner is a significant source of competitive advantage. However, the management of innovation is made difficult by the complexity, unpredictability, and pace of turbulence in the environment, which compresses the time horizons for strategic planning. The main purpose of this study was to investigate innovation management practices in technology-intensive industries and to explore their relationship to company performance. A non-probability judgment sample of companies listed on the Johannesburg Stock Exchange (JSE) was taken. The study makes a contribution to the field of strategic management research by integrating the archetypes of several previous studies to derive a more comprehensive taxonomy of innovation strategy archetypes. Two distinct innovation strategy factors obtained with the analysis were proven to positively influence the company performance archetypes and were classified as New Product Innovation and Process Innovation factors. The results show that innovation strategy choices can significantly affect company performance. It thereby indicates which of the underlying archetypes have the strongest relationship with company performance. From an industry perspective, the greatest significance of these findings may be that they accentuate the importance of innovation policy in strategic management. The substantial differences in performance associated with the archetypes do not necessarily indicate that a given company should choose a particular innovation strategy, but rather indicates that innovation policy decisions may have a substantial leverage on a company's performance and should be analysed and exercised with care.
\end{abstract}

Keywords: Company Performance; Innovation Policy; New Product Innovation; Process Innovation

\section{INTRODUCTION}

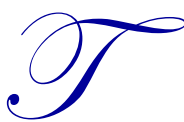

he reduction of trade barriers and the deregulation of industries have intensified competition in many areas of business. For technology intensive companies, the pace of advancements in technology further intensifies the dynamics of the competition. The ability of discontinuous technological innovations to change the rules of competition, even eliminate the boundaries between industries, can have an enormous impact on the performance and survivability of companies. It is, therefore, imperative for companies to be able to adapt and evolve if they wish to survive. International business literature suggests that companies develop competitive advantages in order to ensure success in current markets (Hamel \& Prahalad, 2006; Levitt, 1983; Ohmae, 1989; Panagiotou, 2007; Pérez-Luño \& Cambra, 2013). Such advantages tend to be monopolistic assets, either tangible or intangible (Clemens, 2006), such as new technology, patented products, product development capability, and marketing skills. In a dynamic global market, companies that generate competitive advantages by effectively integrating research and development, production and marketing activities, tend to ultimately succeed.

In order to acquire advantages, companies may develop technical knowledge from internal and/or external sources. Experience curve advantage may therefore be developed by companies that can successfully accumulate integrated knowledge in their business operations. Studies (e.g., by Pérez-Luñoa et al., 2011) have shown that one of the important factors for successful innovation is good coupling among design, development, production, and marketing functions. Companies that fail to synthesise these functional activities could result in business collapse (Ohmae, 1989). The importance of learning from technology has been emphasised by Freeman (1994), but technical knowledge can hardly be obtained without the necessary processing and modification. Mature companies, especially, have difficulty adapting to changes in technology (Hamel, \& Prahalad, 2006). 
In coming years, the widely acknowledged importance of technology will grow, increasing the wager executives must place on their companies' ability to compete through technology (Shoham \& Fiegenbaum, 2002). The cutting edge of technology management, however, goes beyond basic research and development (R\&D) expenditures. Increasingly, corporate strategists are making a more precise distinction between "technology" and "technology management." Technology addresses the application of scientific and engineering knowledge to the solution of problems. Technology management, however, has a broader charter as it is the integration of technology throughout the organisation as a source of sustainable competitive advantage (Harmon \& Davenport, 2007).

\section{LITERATURE REVIEW}

The ability to innovate and exploit innovations globally in a rapid and efficient manner is a significant source of competitive advantage (Song et al., 2013). However, the management of innovation is made difficult by the complexity, unpredictability, and pace of turbulence in the environment, which compresses the time horizons for strategic planning (Shin \& Lee, 2013). Some management scientists believe that innovation is one of the principal methods through which organisations could adapt to and manage their environments (Dahan \& Shoham, 2014). Research has shown that industry leaders are noticeably more innovative than their competitors and those innovative companies are more successful in terms of turnover and profits (Pérez-Luño \& Cambra, 2013). Further, it has been suggested that innovation creates competitive advantage and that a continuous stream of innovations is a vital component of long-term survival (Dahan \& Shoham, 2014; Hamel \& Prahlad, 2006).

An increasing number of management scientists believe that, in addition to short-term profits, top management has the responsibility to create a strategic capacity for continuous renewal within the organisation. Renewing the company's strategic potential and, in fact, long-term survival, means that significant resources should be allocated to the strategic processes of envisioning the future, imagining what could be, and creating new competitive spaces. Innovation is a significant component in achieving these objectives (Hamel \& Prahlad, 2006). Following an extensive series of interviews of top managers who were accountable for profitability in their strategic business areas in twelve multinational companies, Zien \& Buckler (1997) conclude that:

Leaders in highly innovative companies demonstrate in every decision, action and communication that innovation propels profitability and that continued innovation is the soul of the company.

\section{Innovation Defined}

While there are many arguments and debates in virtually all fields of management, it seems that this is particularly the case in innovation management. When an attempt is made to define terms such as new, creativity, or discovery, it often results in a game of semantics. First, what is new to one company may be old to another. Second, is success determined in terms of commercial gain or in terms of scientific achievement? Third, it is context dependent - what is viewed as a success today may be viewed as a failure in the future (Garnett \& Pelser, 2007).

The terms "creativity" and "innovation" are often used interchangeably in research studies, and the distinction between the two concepts may be more one of emphasis than of substance (Song et al., 2013). Nonetheless, some agreement about the terms' definitions has emerged recently - creativity has to do with the creation of novel and useful ideas (Ensminger et al., 2004), while innovation relates to the creation or adoption of useful ideas and idea implementation (Hung-Chia, 2013). Innovation is a very broad concept that can be understood in a variety of ways. One of the more comprehensive definitions is offered by Myers \& Marquis (1969):

Innovation is not a single action but a total process of interrelated sub-processes. It is not just the conception of a new idea, nor the invention of a new device, nor the development of a new market. The process is all these things acting in an integrated fashion.

Most management scholars distinguish innovation from invention by suggesting that innovation is concerned with the commercial and practical application of ideas or inventions. Invention, then, is the conception of the idea, whereas innovation is the subsequent translation of the invention into the economy (Ensminger et al., 2004). The following equation provides an illustration of the relationship between the two terms (Pelser, 2001): 
Innovation $=$ Conception + Invention + Exploitation

The conception of new ideas is the starting point for innovation. A new idea by itself, while interesting, is neither an invention nor an innovation; it is merely a concept that is novel with respect to some frame of reference; e.g., individual, departmental, organisational, or all accumulated knowledge. The process of converting intellectual thoughts into reality (usually a product or process) is an invention (Hung-Chia, 2013). This is where science and technology usually play a significant role. At this stage, inventions need to be converted into products that will improve company performance. Therefore, exploitation normally implies wide acceptance and/or profitability resulting from the invention (Dahan \& Shoham, 2014).

This introduces the notion that innovation is a process with a number of distinctive features that have to be managed (Rauch et al., 2009). The following definition of innovation, which acknowledges that innovation depends on inventions but that inventions need to be harnessed to commercial activities before they can contribute to the growth of a company, will be used in the study:

Innovation is the management of all activities involved in the process of idea generation, technology development, manufacturing and marketing of a new or improved product or manufacturing process or equipment. (Trott, 1998)

\section{Innovation Strategy Archetypes}

Innovation policies encompass both the contents of innovation strategies and the processes of innovation management. The seminal work from Rothwell (1992) provides an extensive synopsis of key factors that appear to emerge in many studies in relation to companies that are technically progressive or associated with successful innovation. According to Rothwell (1992), following are eight key factors underpinning successful innovation:

1. Establishing effective linkages with external institutions and bodies of technical know-how, creating good internal and external communication, and possessing a willingness to accept and adopt external ideas

2. Treating innovation as a corporate-wide task, implementing functional integration by incorporating all departments in the project at the earliest stage possible, and designing for "marketability"

3. Implementing careful planning and project control procedures, making up-front commitment of resources to screening projects, and regularly appraising projects

4. Stressing efficiency and high quality work, implementing quality control procedures, and utilising effectively up-to-date production equipment

5. Building a strong market orientation, with an emphasis on user-needs, and building customer linkages that involve users in the development process

6. Providing a good technical service to customers, training customers, and ensuring effective and efficient supply of spares

7. Possessing the presence of certain key individuals, product champions, technological gatekeepers, etc.

8. Having high quality management - dynamic and open minded, being able to attract and retain talented managers and researchers, and applying commitment to developing human capital

These eight factors were later synthesised by Pelser (2001) in the following innovation strategy archetypes:

1. Product Innovation

2. Process Innovation

3. Marketing Innovation

4. Management Innovation

\section{Technological Innovation Strategies}

In the early 1980's, Porter (1980) made a major contribution to the analysis of innovation in corporate strategy by explicitly linking technology to the "five forces" driving industry competition and to the choice amongst a set of "four generic strategies" that must be made by the company. According to Porter (1980), the goal of competitive strategy is to find a position in an industry where a company can best defend itself against these five 
competitive forces or can influence them in its favour. Porter (1983) was among the early strategy researchers to note the lack of research linking technological change and competitive strategy. His article proceeds to relate technology strategy to his three generic competitive strategies - overall cost leadership, overall differentiation, and a narrow business segment focus.

A set of alternative technological innovation strategies, in terms of timing of technology entry into the market, together with the extent of its segmentation and specialisation, were developed by Pelser (2001). The classification is summarised in detail in Table 1. It should be stressed that the classification scheme constitutes a continuum rather than a number of discrete types. Each strategy may overlap into others and a company or strategic business unit may pursue one or more strategies simultaneously in different product-market areas.

Table 1: The Derivation of Technology Strategy Dimensions

\begin{tabular}{|ll|c|c|c|c|c|}
\hline \multicolumn{1}{|c|}{ Function } & Offensive & Defensive & Imitative & Specialist & Dependent \\
\hline - & Non-directed fundamental research & Medium & Medium & None & None & None \\
\hline - & Applied directed research & High & Medium & None & None & None \\
\hline - & Experimental development and design & High & High & None & Medium & None \\
\hline - & Advanced development and design & High & High & High & High & Low \\
\hline - & Pilot/prototype to full production & Medium & Medium & High & Medium & Medium \\
\hline - & Quality control or product design & Medium & Medium & High & Medium & Medium \\
\hline - & Patents and licenses & High & Medium & Low & Medium & None \\
\hline - & After-sales services & High & Medium & High & High & Medium \\
\hline - & Education and advisory services & High & Medium & Low & High & Medium \\
\hline - & Long-term planning & High & Medium & Low & High & None \\
\hline
\end{tabular}

Source: Pelser (2001)

The offensive strategy (also known as leader strategy) centres on the advantages to be gained from a monopoly of the technology. The primary motive of this strategy is to ensure that the product is launched into the market before the competition. Offensive innovators are characterised by low stability and predictability. The technology life cycle model suggests that relatively good profit opportunities occur in the performance maximising stage in the cycle when the innovation has been initially marketed, but the dominant design has yet to emerge. Further, it also stresses that new product and company mortality rates are at a peak in this stage of the cycle. These two considerations make a defensive strategy (also known as "follow-the-leader" strategy) very attractive for a company. The imitative strategy is focused on low-cost production and success is dependent on achieving economies of scale in manufacturing. The imitative company will be development design, production, and service engineering intensive rather than research intensive. Companies who undertake an astute analysis of the primary innovator's strengths, weaknesses, and strategies, combined with a search for unrecognised applications, will frequently discover niches which can be profitably exploited (the specialist strategy). Most of these companies emphasise design and development for a niche in the market, which is too small to interest the larger primary innovators but still economically large and technologically demanding. When a company's technology base is condensed to the functional areas - production, marketing, and their secondary functions, it usually follows a dependent strategy. According to Pelser (2001), it normally is a subsidiary or specialist department of a larger company.

\section{Company Performance}

Zahra \& Hayton (2008) determined that the literature on performance is very extensive but that it shows a lack of consensus as to the meaning of the term. Brush \& Vanderwerf (1992) point out that the use of the term "performance" by researchers includes many constructs measuring alternative aspects of performance. This is consistent with the finding of Murphy et al. (1996) who, after a comprehensive literature review, were able to isolate a total of 71 different measures of performance. In spite of this apparent abundance, the vast majority of studies have used financial measures of performance (Murphy et al., 1996). The raison d'être for this fixation with financial performance measures is found partly in the fact that financial performance is at the core of the organisational control systems and partly in that it is one of the most easily quantifiable measuring instruments. For example, Lussier (1995) argues that in studying the benefits of technology, instead of analysing macro-economic data from 
governmental statisticians, micro-economic corporate financial results that are certified by auditors should be used. However, this has caused empirical research to rely on a narrow set of accounting measures of financial performance, such as return on investment (ROI), return on assets (ROA), or earnings per share (Pandian et al., 2006; Sapienca et al., 1988).

When using accounting measures for measuring company performance, a number of issues should be taken into consideration. First, financial records are, in general, difficult to interpret, even if accurate financial data are reported (Cooper, 1979). Second, absolute numbers on financial performance criteria are affected by industryrelated factors (Miller \& Toulouse, 1986). Directly comparing financial data for companies in different industries could be misleading; even if the sample contains companies from the same industry sector, they may include companies operating in different markets. Third, accounting measures may be susceptible to accounting method variation and, lastly, accounting measures are not always representative of the actual performance of the companies as many company directors, for a variety of reasons, manipulate performance reporting.

Despite the fact that financial performance is evidently important for the company, it draws only on the economic dimension of performance, neglecting other important goals of the company. This argument is supported by Zahra \& Covin (1994) who argues that research which considers only a single performance dimension or a narrow range of performance constructs (e.g., multiple indicators of profitability) may result in misleading descriptive and normative theory building. According to the author of this study, it is unlikely that any single performance measure or dimension could serve the needs of a diverse set of research questions. This view is also shared by Zahra \& Hayton (2008) who point out that a multi-dimensional construct provides an alternative in establishing valid operational definitions. Further to this, Murphy et al. (1996) argue that a distinction between performance measures should be done on the grounds of whether the sources are secondary data (also known as archival) versus primary data (e.g., questionnaire interview).

The innovation management organisation (IMO) is responsible for developing new products and technologies (Pérez-Luñoa et al., 2011). Science and technology from the external environment are combined with the company's in-house skills, knowledge, and competencies to develop new products and technologies. The responsibilities that fall within the domain of innovation management encompass research and development (R\&D). For this reason, $R \& D$ consists of those activities and responsibilities, ranging from understanding progressive technology to generating ideas to developing new products and technologies. Understanding the dynamics of the innovation management organisation (IMO) is important in understanding the role and impact of strategic leadership of innovation in technology intensive companies. Therefore, conceptual definition is the extent to which the R\&D manager or other top manager perceives that the IMO has achieved its desired objectives over the last three years.

\section{PROBLEM STATEMENT AND RESEARCH QUESTIONS}

It is increasingly evident that investments, sophisticated technological expertise, and strong national and corporate leadership are no guarantee for continuing economic success and long-term survival. At the corporate level, it is often more critical for a company to channel all its available resources into where the market demands are and where they can do better than their competitors. The theory is not new. Most managers know that in order to survive, their organisations have to constantly improve themselves in every conceivable way. As competitive pressures increase, the need to continuously adapt, develop, and innovate has become a basic building block for organisational excellence. Weaknesses to innovate eventually lead businesses to stagnate and fade away in the face of a dynamic environment. The thesis is to make innovation the core of the corporate strategy and an integral part of a comprehensive forward-looking new product development program.

There is a critical need to understand the key factors that lead to innovation excellence, the organisational and environmental innovation, and the importance of innovation strategies. The main purpose of this study is to investigate innovation strategies in widespread use in technology-intensive industries and to explore their relationship to company performance. The problem addressed in the study is the need for a better understanding of the role that innovation archetypes play in determining company performance. The study focuses on two central questions: 
1. What are the prevalent innovation strategy archetypes being employed by South African companies in technology-intensive industries?

2. What relationships can be observed between the innovation strategy archetypes and company performance?

\section{RESEARCH METHODOLOGY}

The data gathering and analysis phase of the study had the following three objectives.

1. Gathering data along key innovation strategy archetypes from R\&D managers of technology intensive companies

2. Gathering objective data about the performance (input and output) of those companies selected for the study

3. Analysing the data using multivariate statistical methods to explore the relationships among the innovation strategy archetypes and company performance

\section{Data Requirements}

A survey of R\&D managers of companies listed on the Johannesburg Stock Exchange (JSE) was conducted through the use of a questionnaire. The South African context was chosen both from an operational purpose and the objective to compare the findings with those obtained from studies conducted in other countries or regions. Since the performance of companies in technology intensive industries could be more affected by technology policies than by the performance of companies in other industries, it was assumed that companies in technology industries would be more likely to have innovation strategies, thereby making it easier to observe the relationships of interest.

R\&D managers from 200 South African technology intensive companies were asked to complete a selfadministered electronic questionnaire designed to gather data regarding their company's innovation policies. The questionnaire requested data on the specific industry in which the company operates; the innovation strategy of the company, and the processes the company employs to develop and implement the strategy. Eighty-four valid responses were ultimately received and used in the study.

The innovation strategy (content) archetypes are the result of a substantial body of prior research which were synthesised into the following four archetypes (Pelser, 2001):

1. Product Innovation is the commercialisation of a new product. It is measured in terms of the emphasis a company places on a stated and working strategy of product innovation and the way it evaluates product innovation's performance relative to objectives:

- Have a stated and working strategy of product innovation

- Evaluate product innovation's performance relative to objectives

2. Process Innovation refers to technologies, techniques, systems, and procedures that are involved in transforming inputs into outputs. It is measured in terms of the emphasis a company places on a stated and working strategy of process innovation and the way it evaluates process innovation's performance relative to objectives:

- Have a stated and working strategy of process innovation

- Evaluate process innovation's performance relative to objectives

3. Marketing Innovation refers to marketing activities that are involved in integrating the customer needs with the company's profit needs. It is measured in terms of the emphasis a company places on a stated and working strategy of marketing innovation and the way it evaluates marketing innovation's performance relative to objectives:

- Have a stated and working strategy of marketing innovation

- Evaluate marketing innovation's performance relative to objectives

4. Management Innovation refers to management activities and key responsibilities utilising available resources to strategically position the company in the environment to meet its goals and objectives. It is 
measured in terms of the emphasis placed on a stated and working strategy of management innovation and the way management evaluates innovation's performance relative to objectives:

- Have a stated and working strategy of management innovation

- Evaluate management innovation's performance relative to objectives

Each dimension was measured through the use of two items in the questionnaire. The questionnaire items were designed to permit answers on a five-point interval or Likert Scale. A survey questionnaire was developed and tested in a small pilot study in order to assess the clarity of the directions and questionnaire items. It was then revised and submitted to five technology strategists to confirm its intelligibility and cognitively confirm the validity of the study archetypes and variables as relating to important factors in strategic management of technology.

A number of company performance archetypes were used as the dependent variables in the analysis of the study. Despite the fact that financial performance is evidently important for the company, it draws only on the economic dimension of performance, neglecting other important goals of the company. This argument is supported by Zahra \& Covin (1994) and Pandian et al. (2006) who argue that research that considers only a single performance dimension or a narrow range of performance constructs (e.g., multiple indicators of profitability) may result in misleading descriptive and normative theory building. Hansen (2010) and Murphy et al. (1996) pointed out that it is unlikely that any single performance measure or dimension could serve the needs of a diverse set of research questions. The selection of the company performance archetypes resulted in six dependent variables which were classified in the following two dimension groups:

1. $\quad$ Effectiveness of the IMO - (four input dependent variables)

2. Performance of the company - (two output dependent variables)

The measures selected for this study demonstrate strong relationships with company performance and had been reviewed in the literature section:

1. Contribution to sales (i.e., right product at the right time)

2. Efficiency of innovation project management (i.e., project success rate)

3. Impact of the innovations (e.g., degree of novelty or technical impact)

4. $\quad R \& D$ expenditure (i.e., investment in R\&D activities)

5. $\quad$ Patent information (i.e., output of $R \& D$ activities)

6. $\quad$ Return on assets (i.e., company financial performance)

Factor analysis was used to reduce the archetypes into identifiable factors. Pearson r-correlation was then used to find the strength and direction of the relationships between the factors and the performance archetypes. The relationships examined are those between the independent variables and the effectiveness of the innovation management organisation (IMO) and the performance of the company.

\section{Sample Selection}

A non-probability, judgment sample of companies listed on the Johannesburg Stock Exchange (JSE) was taken. It was decided to use listed companies on the JSE for two primary reasons: (1) Listed companies display a capacity and capability (capital and human resources) for R\&D activities compared to smaller unlisted companies and (2) Quantifiable data (e.g., annual reports) is more readily available for the external stakeholders of listed companies than it is on unlisted companies. The motivation for using the judgment method in sampling was to build a database of those companies most likely to be associated with manufacturing products and/or investing in R\&D activities. Based on the above-mentioned screening criteria, it was decided to use the Industrial Consumer sector.

For the study, the following two important criteria were established to select the appropriate companies or divisions within the Industrial Consumer sector:

1. New product development activities which included tangible and intangible products. Contact details for the R\&D manager or designated top manager responsible for research and development 
Two hundred companies or divisions were identified and incorporated into the survey after the screening stage. Feedback was received from $89 \mathrm{R} \& \mathrm{D}$ managers of these two hundred companies, stating their willingness to participate in the survey. A total of 84 completed responses were received and captured for the study. This translates to a 42 percent response rate from the base of 200 originally identified companies. However, compared to the feedback received from the 89 respondents, it effectively means that the filtered response rate equates to 94 percent. The non-response portion of the original sample of 200 companies is comprised of 64 companies. An additional 24 companies have indicated that they are not involved in any type of R\&D activities, which automatically excluded them from the study. Another 23 companies provided feedback or reasons concerning their non-participation in the survey, which ranges from vacant positions in R\&D key functions to a lack of interest of these types of research efforts.

A breakdown of the respondents per industry is presented in Figure 1. Compared to the other sectors, technological opportunities are higher in science based sectors - chemicals, oils and plastics; electronic and electrical; IT and telecommunications. These companies also emphasise more on product innovation than process innovation and represent 58 percent of the respondents.

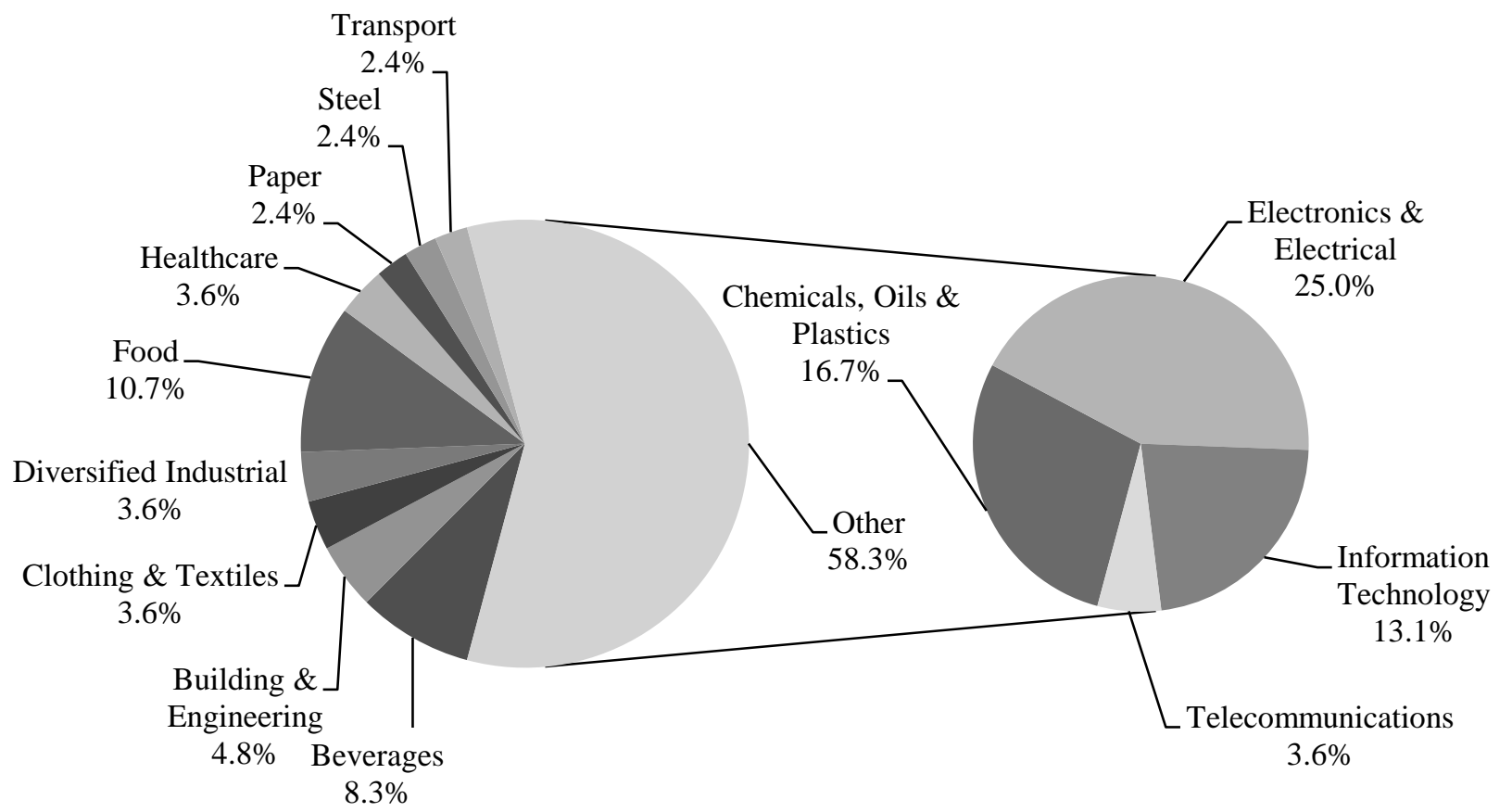

Figure 1: Surveyed Companies by Industry

\section{ANALYSIS OF RESULTS}

\section{Descriptive Statistics: Innovation Strategy Archetypes}

The basic descriptive statistics of central tendency and measures of variability for the innovation strategy archetypes are shown for variables A13 - A20 in Table 2. The range corresponds to the numerical value of 4 . The minimum value (1) refers to the response alternative - substantially less - and the maximum value (5) refers to the response alternative substantially more. The highest mean response turns out to be 3.42 for variable A13. The arithmetic average of the responses for variable A13 indicates that the sample of companies has a stated and working strategy of product innovation, somewhat more than do their competitors. The lowest mean response turns out to be 3.02 for variable A18. This suggests that the sample is at the same level as that of their competitors when it comes to evaluating marketing innovation's performance relative to objectives. The standard error of the mean is a measure of how much the value of the mean may vary from sample to sample taken from the same distribution. In 
this particular section of the analysis, the values are relatively small, which indicates that the current sample may vary slightly from another sample. The largest standard deviation is 1.32 for variable A19 and the smallest is 0.79 for variable A16. It can be concluded that the sample is relatively homogenous and, consequently, the mean of this section gives a good indication of the responses. The skewness measures obtained for the innovation strategy variables indicate that four of the variables (A13, A15, A16, and A17) have negatively skewed distributions (values smaller than 0). However, the other four variables (A14, A18, A19, and A20) have positively skewed distributions (values bigger than 0 ). None of the variables fall outside the -1 range, which indicates normal skewed distributions. The kurtosis values obtained for all of the variables in Table 2 indicate relatively flat distributions (negative values).

Table 2: Descriptive Statistics - Innovation Strategy Archetypes

\begin{tabular}{|c|c|c|c|c|c|c|c|c|c|c|c|c|}
\hline \multirow{2}{*}{ Variable } & \multirow{2}{*}{$\mathbf{N}$} & \multirow{2}{*}{ Range } & \multirow{2}{*}{ Min } & \multirow{2}{*}{ Max } & \multicolumn{2}{|c|}{ Mean } & \multirow{2}{*}{$\begin{array}{c}\text { Std. } \\
\text { Deviation }\end{array}$} & \multirow{2}{*}{ Variance } & \multicolumn{2}{|c|}{ Skewness } & \multicolumn{2}{|c|}{ Kurtosis } \\
\hline & & & & & Statistic & Std Error & & & Statistic & Std Error & Statistic & Std Error \\
\hline A13 & 84 & 4.00 & 1.00 & 5.00 & 3.4167 & .1164 & 1.0666 & 1.138 & -.235 & .263 & -.123 & .520 \\
\hline A14 & 84 & 4.00 & 1.00 & 5.00 & 3.1786 & .1188 & 1.0884 & 1.185 & .037 & .263 & -.496 & .520 \\
\hline A15 & 84 & 4.00 & 1.00 & 5.00 & 3.3095 & .1057 & .9691 & .939 & -.825 & .263 & -.002 & .520 \\
\hline A16 & 84 & 4.00 & 1.00 & 5.00 & 3.1429 & .0866 & .7937 & .630 & -.559 & .263 & -.353 & .520 \\
\hline A17 & 84 & 4.00 & 1.00 & 5.00 & 3.2262 & .1225 & 1.1232 & 1.261 & -.096 & .263 & -.942 & .520 \\
\hline A18 & 84 & 4.00 & 1.00 & 5.00 & 3.0238 & .1301 & 1.1921 & 1.421 & .041 & .263 & -.822 & .520 \\
\hline A19 & 84 & 4.00 & 1.00 & 5.00 & 3.0952 & .1443 & 1.3228 & 1.750 & .141 & .263 & -1.149 & .520 \\
\hline A20 & 84 & 4.00 & 1.00 & 5.00 & 3.1548 & .1412 & 1.2940 & 1.675 & .012 & .263 & -1.063 & .520 \\
\hline
\end{tabular}

\section{Descriptive Statistics: Company Performance Archetypes}

The descriptive statistics of central tendency and measures of variability for the company performance archetypes are shown for variables B31 - B36 in Table 3. No missing values (N) were encountered with the data capturing process. The range for variables B31 - B34 is 5. The values assigned to this set of responses run from 1 through 6 and therefore form an ordinal scale. However, variables B35 - B36 conform to all the properties of the previously-mentioned scales. These quantified responses form a ratio scale which is defined as a set of numbers in which the ratios between numbers can be meaningfully interpreted (Parasuraman et al., 2007). Two measures of central tendency are meaningful for the ordinal-scaled responses (B31 - B34) - the mode as a number depicting the "middle" position in the range of responses and the median; that is, the category in which the 50th percentile response falls when all responses are arranged from lowest to highest (or vice versa). Referring to Table 3, variable B31 realised a mode of $2(10-24 \%)$ for the percentage of sales over the last three years due to new products.

The percentage of innovation projects that earned a profit over the last three years (variable B32) corresponds to the response option (1) of less than 10\%. The same mode applies to variable B33 (innovations as new-to-the-world breakthroughs) and B34 (R\&D expenditure as a percentage of sales) for a rank order of less than $10 \%$. The quantified responses to variables B35 and B36 are classified as metric data on the ratio scale. The mean for the three-year-average number of patents registered (variable B35) per year is 2.45 patents, with a high standard deviation of 3.42. However, the most frequently recurring response (mode) was 0 patents reported by respondents. The mean for the company's three-year-average return on assets (variable B36) is 21.24 percent. Multiple modes have been calculated for variable B36 and for that reason, no mode is indicated. If the calculated values of skewness and kurtosis exceed a critical value, then the distribution is non-normal. A value exceeding \pm 2.58 indicates that the assumption about the normality of the distribution at the .01 probability level can be rejected. At the .05 error level, the critical value is \pm 1.96 . All the above-mentioned variables (A1 - B36) are within the limits of the critical values, thus indicating normality (Hair et al., 2010).

Table 3: Descriptive Statistics - Company Performance Archetypes

\begin{tabular}{|c|c|c|c|c|c|c|c|c|c|c|c|c|}
\hline \multirow{2}{*}{ Variable } & \multirow{2}{*}{$\mathbf{N}$} & \multirow{2}{*}{ Range } & \multirow{2}{*}{ Min } & \multirow{2}{*}{$\operatorname{Max}$} & \multirow{2}{*}{$\begin{array}{c}\text { Mean } \\
\text { Statistic }\end{array}$} & \multirow{2}{*}{$\begin{array}{c}\text { Std } \\
\text { Deviation }\end{array}$} & \multirow{2}{*}{ Median } & \multirow{2}{*}{ Mode } & \multicolumn{2}{|c|}{ Skewness } & \multicolumn{2}{|c|}{ Kurtosis } \\
\hline & & & & & & & & & Statistic & Std Error & Statistic & Std Error \\
\hline B31 & 84 & 5.00 & 1.00 & 6.00 & 2.9167 & 1.4579 & 3.00 & 2.00 & .483 & .263 & -.858 & .520 \\
\hline $\mathbf{B 3 2}$ & 84 & 5.00 & 1.00 & 6.00 & 2.7143 & 1.4106 & 3.00 & 1.00 & .394 & .263 & -.792 & .520 \\
\hline B33 & 84 & 5.00 & 1.00 & 6.00 & 2.2024 & 1.4790 & 2.00 & 1.00 & 1.084 & .263 & -.074 & .520 \\
\hline B34 & 84 & 5.00 & 1.00 & 6.00 & 2.0238 & 1.2319 & 2.00 & 1.00 & 1.142 & .263 & .337 & .520 \\
\hline B35 & 84 & 14.00 & .00 & 14.00 & 2.4524 & 3.4165 & .00 & .00 & 1.316 & .263 & .872 & .520 \\
\hline B36 & 84 & 62.00 & -15.00 & 47.00 & 21.2381 & 12.3255 & 22.50 & Multiple & -.548 & .263 & .118 & .520 \\
\hline
\end{tabular}




\section{Descriptive Statistics: Innovation Strategies}

In determining the technological innovation strategy employed by each company, six strategy types were formulated (Table 4). Two of the response options of variable B38 represent 60 percent of the respondents' choices. Launching products into markets before the competition and emphasising design and development for a niche in the market are corresponding to the offensive and specialist innovation strategy alternatives selected for the study.

Table 4: Innovation Strategies

\begin{tabular}{|l|c|c|c|c|}
\hline \multicolumn{1}{|c|}{ Variable B38 } & Frequency & Percent & Valid Percent & Cumulative Percent \\
\hline Offensive & 36 & 42.9 & 42.9 & 42.9 \\
\hline Defensive & 10 & 11.9 & 11.9 & 54.8 \\
\hline Imitative & 7 & 8.3 & 8.3 & 63.1 \\
\hline Specialist & 18 & 21.4 & 21.4 & 84.5 \\
\hline Dependent & 6 & 7.1 & 7.1 & 91.7 \\
\hline Other & 7 & 8.3 & 8.3 & 100.0 \\
\hline Total & 84 & 100.0 & 100.0 & \\
\hline
\end{tabular}

Forty-three percent of the respondents consider their innovation strategy to be offensive and 21 percent of them have selected a specialist innovation strategy (see Figure 2). The remaining 30 respondents opted for the defensive (respond quickly to companies that are first into the market, with better products), imitative (imitate existing products from competitors at lower prices), dependent (rely on the parent company for innovation initiatives), and other strategy options on a scale ranging from $7-12$ percent.

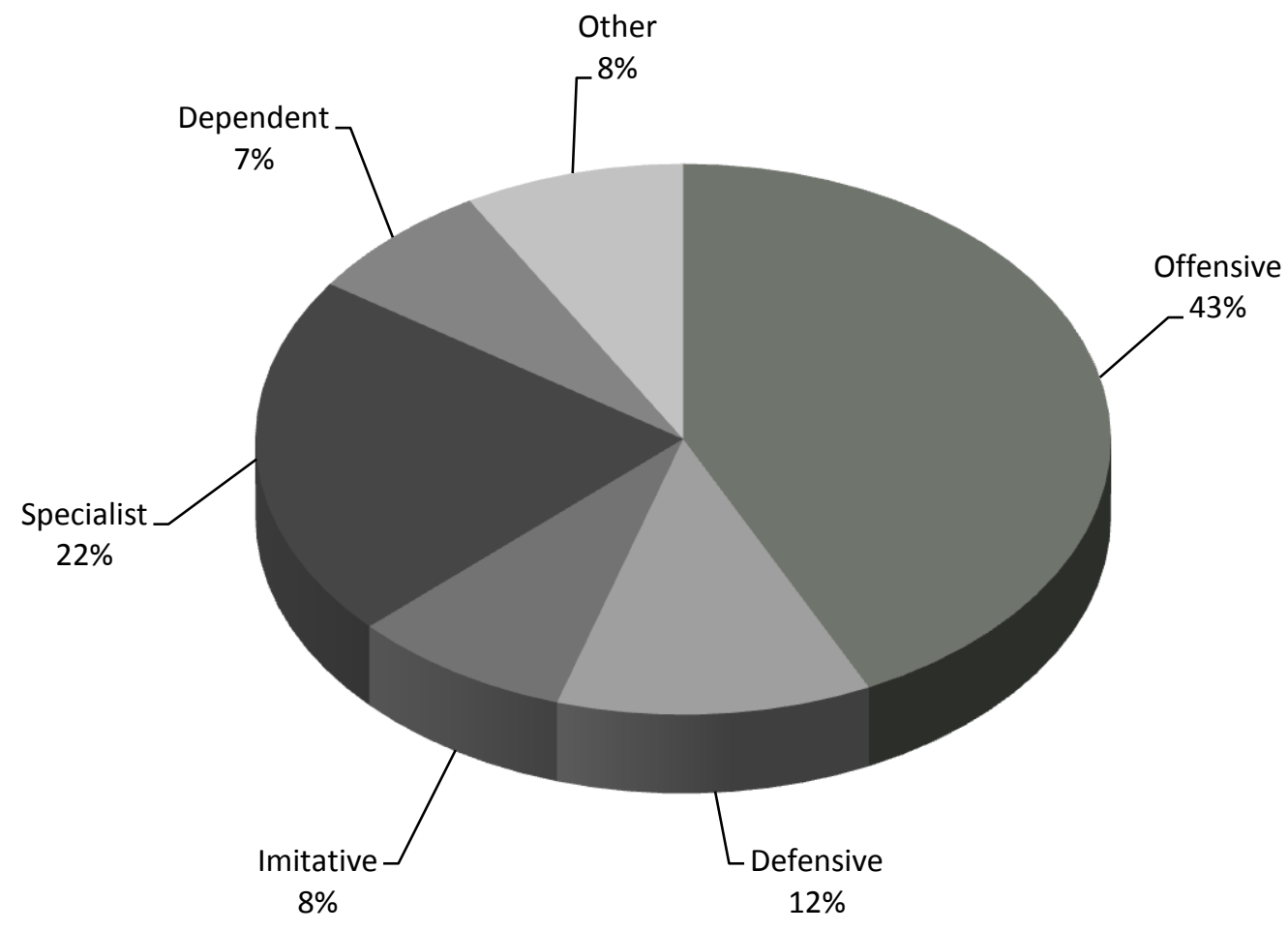

Figure 2: Innovation Strategies

\section{Factor Analysis: Innovation Strategy}

The eight innovation strategy variables (A13 - A20) were factor-analysed by using the principal axis factoring method. Then using the latent root criterion, two factors were extracted on the basis of their Eigenvalues being greater than 1 . Together they accounted for 82.61 percent of the variation in the data. The factors were rotated 
by using the Varimax rotation method. All the variables had correlations greater than .41 and more than 90 percent of the matrix elements were greater than .50. Bartlett's test of sphericity confirmed that the correlation matrix was not an identity matrix. The Kaiser-Meyer-Olsen (KMO) measure, as sampling adequacy, was .770 which Hair et al. (2010) characterised as "middling." This is also defined as an adequate measure, indicating that the degree of correlation between the unique factors was low. The anti-image covariance matrix contained few elements with values greater than 0.9 , again confirming the applicability of factor analysis. The number of factors to be extracted was set at two, based on the Kaiser criterion of selecting factors with Eigenvalues greater than 1 .

The Chi-square statistic was 754.074 with 28 degrees of freedom, which is significant at the .000 level. The reduced set of variables collectively meets the necessary threshold of sampling adequacy and thus the fundamental requirements for factor analysis. The final statistics show that 82.61 percent of the variance was explained by the two factors. The reproduced correlation contained 10 residual values ( 35 percent) greater than .05 , indicating that the model fits the data.

The factors were extracted by using the principal axis-factoring method which extracts factors from the original correlation matrix with squared multiple correlation coefficients placed in the diagonal as initial estimates of the communalities. The factor loadings are used to estimate new communalities that replace the old communality estimates in the diagonal. Iterations continue until the changes in the communalities from one iteration to the next satisfy the convergence criterion for extraction. Principal axis factoring (also known as common factor analysis) is often viewed as more theoretically based than other methods of factoring (Hair et al., 2010). The Varimax (orthogonal rotation) method was used to rotate the factors by minimizing the number of variables that have high loadings on each factor.

The rotated innovation strategy factor loadings are contained in Table 5. As a reminder, each survey respondent was asked to report on the importance of each of the variables to his or her company relative to major competitors. The heaviest factor loading for each variable is formatted in bold font style.

Table 5: Rotated Innovation Strategy Factor Matrix

\begin{tabular}{|l|c|c|c|}
\hline \multicolumn{1}{|c|}{ Variable } & Variable Description & Factor 1 & Factor 2 \\
\hline A20 & Evaluate management innovation's performance & $\mathbf{. 8 7 4}$ & .179 \\
\hline A19 & Have a strategy of management innovation & $\mathbf{. 8 5 1}$ & .300 \\
\hline A17 & Have a strategy of marketing innovation & $\mathbf{. 8 1 7}$ & .324 \\
\hline A18 & Evaluate marketing innovation's performance & $\mathbf{. 8 0 1}$ & .312 \\
\hline A13 & Have a strategy of product innovation & $\mathbf{. 6 9 7}$ & .451 \\
\hline A14 & Evaluate product innovation's performance & $\mathbf{. 6 6 2}$ & .532 \\
\hline A16 & Evaluate process innovation's performance & .251 &. $\mathbf{9 6 5}$ \\
\hline A15 & Have a strategy of process innovation & .321 & $\mathbf{. 7 7 9}$ \\
\hline
\end{tabular}

All of the primary factor loadings used in the factor interpretation exceeded .50 in value. According to Hair et al. (2010), factor loadings greater than \pm .30 are considered to meet the minimal level; loadings of \pm .40 are considered important; and if the loadings are \pm .50 or greater, they are considered more important. Considering the factor loadings, the rotated factors are interpreted below and visually displayed in Figure 3.

New Product Innovation - The Eigenvalue of the first factor was 5.702. The product innovation variables (A13-A14), marketing innovation variables (A17-A18), and the management innovation variables (A19-A20) loaded heavily on this factor. Taken together, this pattern of factor loadings clearly reflects the aggressiveness of a company's new product development program in relation to the product, marketing, and innovation activities.

Process Innovation - The Eigenvalue of the second factor was 1.744. The two process innovation variables (A15-A16) both loaded heavily on this factor. The process innovation variables were selected to measure the emphasis a company places on a stated and working strategy of process innovation and the way it evaluates process innovation's performance relative to objectives. For example, it would measure procedures that are involved in transforming inputs into outputs. 


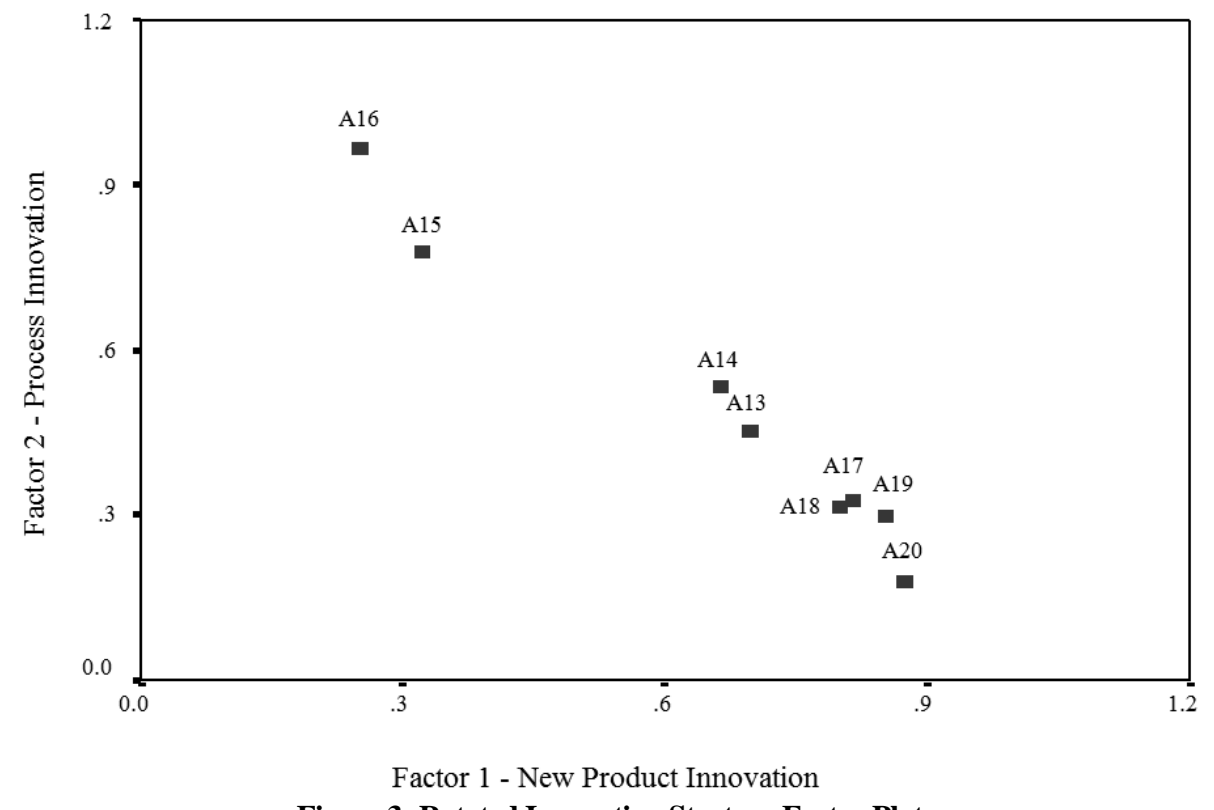

Figure 3: Rotated Innovation Strategy Factor Plot

\section{Factor Analysis: Company Performance}

The methodology for factor analysing the dependent variables was similar to that used for the previous sections. The six company performance variables (B31 - B36) were factor-analysed by using the principal axis factoring method. Then, using the latent root criterion, two factors were extracted on the basis of their Eigenvalues being greater than 1 . Together they accounted for 75.80 percent of the variation in the data. The factors were rotated by using Varimax rotation method. The same number of methods was used to determine the appropriateness of a factor-analytic model for this analysis.

The correlation matrix for the six company performance variables was reviewed to confirm the existence of a substantial number of correlations, which indicates the existence of common factors. All the variables had correlations greater than .16 and more than 40 percent of the matrix elements were greater than .50 . Bartlett's test of sphericity confirmed that the correlation matrix was not an identity matrix.

The Kaiser-Meyer-Olsen (KMO) measure, as sampling adequacy, was .791, which Hair et al. (2010) characterised as "middling." This is also defined as an adequate measure, indicating that the degree of correlation between the unique factors was low. The anti-image covariance matrix contained no elements with values greater than 0.9 , again confirming the applicability of factor analysis.

Based on the Kaiser criterion of selecting factors with Eigenvalues greater than 1, the number of factors to be extracted was set at two. However, the screen test indicates that three factors would be retained. In combining these two criteria, two factors were eventually retained for further analysis because of the very low Eigenvalue (.538) for the third factor. The Chi-square statistic was 235.832 with 15 degrees of freedom, which is significant at the .000 level. The reduced set of variables collectively meets the necessary threshold of sampling adequacy and thus the fundamental requirements for factor analysis.

The final statistics showed that 75.80 percent of the variance was explained by the two factors. The reproduced correlation matrix contained three residual values (20 percent) greater than .05 , indicating that the model fits the data. The rotated company performance factor loadings are contained in Table 6 . The heaviest factor loading for each variable is formatted in bold font style. As a reminder, each respondent was asked to respond to the following questions. 
B31 - Approximately what percentage of sales over the last three years was due to new products?

B32 - Approximately what percentage of innovation projects over the last three years earned a profit?

B33 - Approximately what percentage of innovations could be considered new-to-the-world breakthroughs?

B34 - What is your three-year-average R\&D expenditure as a percentage of sales?

B35 - What is your three-year-average number of patents registered per year?

B36 - What is your company or division's three-year-average ROA?

Table 6: Rotated Company Performance Factor Matrix

\begin{tabular}{|l|c|c|c|}
\hline Variable & Variable Description & Factor 1 & Factor 2 \\
\hline B32 & Efficiency of innovation project management & $\mathbf{. 8 4 1}$ & .308 \\
\hline B33 & Impact of the innovations & $\mathbf{. 7 9 7}$ & .213 \\
\hline B31 & New product contribution to sales & $\mathbf{. 7 7 3}$ & .188 \\
\hline B34 & R\&D expenditure &. $\mathbf{7 5 6}$ & .123 \\
\hline B35 & Patents registered & .089 & .76 \\
\hline B36 & Return on assets & .308 &. $\mathbf{6 1 9}$ \\
\hline
\end{tabular}

All of the primary factor loadings used in the factor interpretation exceeded .50 in value. Considering the factor loadings, the rotated factors are interpreted below and visually displayed in Figure 4.

Input Performance - The conceptual definition for this factor is the extent to which the R\&D or other top manager perceives how the innovation management organisation has achieved its desired objectives over the last three years. The Eigenvalue of the first factor was 3.167. The four input variables (B31 - B34) loaded heavily on this factor. Taken together, this pattern of factor loadings clearly reflects the effectiveness of the innovation management organisation (IMO).

Output Performance - This factor represents the performance of the company where (1) patent information was used to measure R\&D activities and (2) return on assets (ROA) was used to measure company financial performance. The Eigenvalue of the second factor was 1.381. The patent's registered variable (B35) and the return on assets variable (B36) loaded heavily on this factor, indicating the degree of fit for this performance measure.

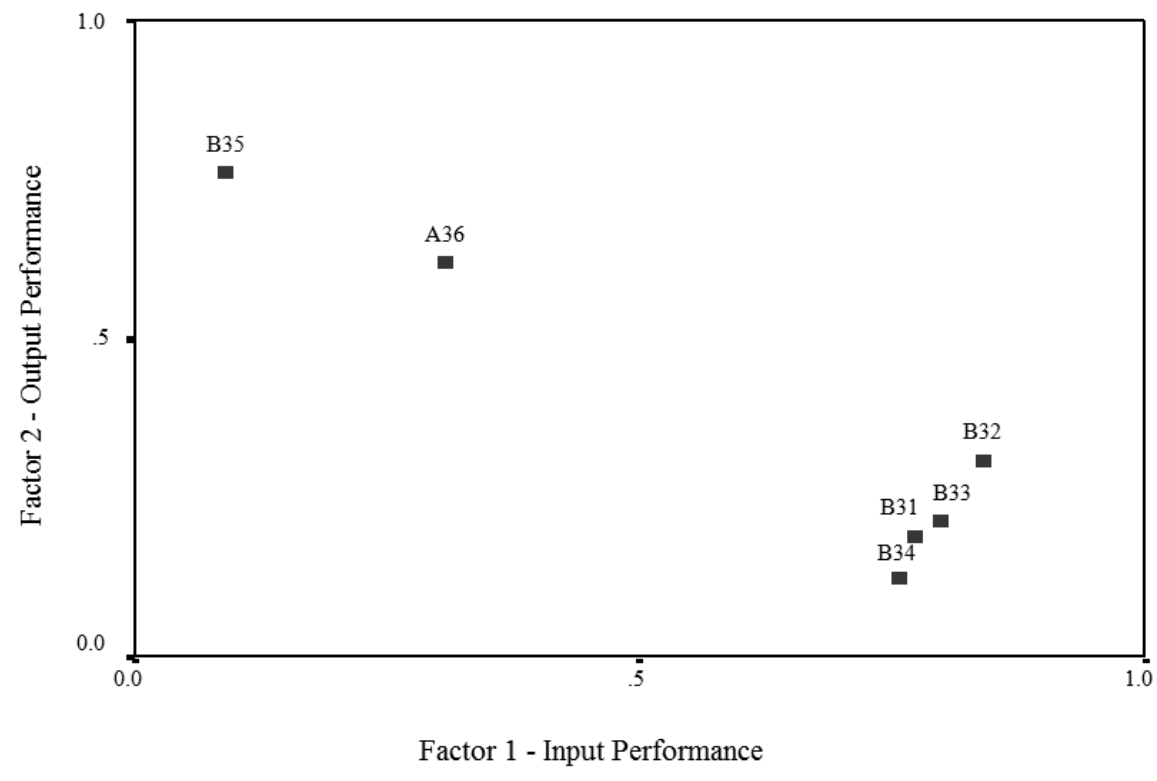

Figure 4: Rotated Company Performance Factor Plot

\section{Reliability and Validity}

The data analysis proceeds by evaluating the survey responses according to the four archetypes for validity and reliability. The summated scales of the study provide two specific benefits. First, it provides a means of 
overcoming the measurement error inherent in all measured variables. A second benefit of the summated scale is its ability to represent the multiple aspects of a concept in a single measure; e.g., the technology focus factor. However, four issues basic to the construction of any summated scale must be addressed before applying them (Hair et al., 2010).

Content validity is the first issue which subjectively assesses the correspondence between individual items and the concept through ratings by expert judges, pre-tests, and other means. Content validity of the questions was obtained from the pilot study and the cognitive confirmation from the five technology experts. The second issue, which is validated by the high factor loadings (greater than 0.5) of the extracted factors, concerns the test of unidimensionality. According to Anderson et al. (1987), each summated scale should consist of items loading highly on a single factor.

The third issue concerns the degree of consistency between multiple measurements of a variable, known as reliability. The consistency of the survey data was assessed by using Cronbach's coefficient alpha, which measures the consistency of the entire scale. The Cronbach alpha computations for the four extracted factors are shown in Table 7. For the new product innovation, it is .9418; for the process innovation, it is .9093; and for the input performance, it is .8887 . These high values indicate a high degree of data stability.

Table 7: Reliability Analysis

\begin{tabular}{|c|c|c|c|c|c|}
\hline Variable & $\begin{array}{c}\text { Scale mean if item } \\
\text { deleted }\end{array}$ & \begin{tabular}{|c} 
Scale variance if item \\
deleted
\end{tabular} & $\begin{array}{c}\text { Corrected item total } \\
\text { correlation }\end{array}$ & Alpha if item deleted & Alpha \\
\hline \multicolumn{6}{|c|}{ New Product Innovation (NPI) } \\
\hline A13 & 15.6786 & 28.8713 & .7994 & .9343 & \multirow{6}{*}{.9418} \\
\hline A14 & 15.9167 & 28.7761 & .7888 & .9353 & \\
\hline A17 & 15.8690 & 27.8501 & .8486 & .9283 & \\
\hline A18 & 16.0714 & 27.3924 & .8301 & .9302 & \\
\hline A19 & 16.0000 & 25.8313 & .8620 & .9268 & \\
\hline A20 & 15.9405 & 26.3940 & .8350 & .9301 & \\
\hline \multicolumn{6}{|c|}{ Process Innovation (PI) } \\
\hline A15 & 3.1429 & 6299 & .8503 & - & \multirow{2}{*}{.9093} \\
\hline A16 & 3.3095 & .9392 & .8503 & - & \\
\hline \multicolumn{6}{|c|}{ Input Performance (InP) } \\
\hline B31 & 6.9405 & 13.3820 & .7446 & .8617 & \multirow{4}{*}{.8887} \\
\hline B32 & 7.1429 & 13.0637 & .8234 & .8305 & \\
\hline B33 & 7.6548 & 13.1685 & .7540 & .8584 & \\
\hline B34 & 7.8333 & 15.1044 & .7130 & .8741 & \\
\hline \multicolumn{6}{|c|}{ Output Performance (OutP) } \\
\hline B35 & 21.2381 & 151.9185 & .5015 & - & \multirow{2}{*}{.4104} \\
\hline B36 & 2.4524 & 11.6724 & .5015 & - & \\
\hline
\end{tabular}

Looking at Table 7, it is evident that the output performance factor coefficient alpha is only .4104. However, the data accuracy aspect of reliability can be tested by comparing the test data with external criteria that measure the same variable. In this study, the self-reported company return on asset variable (B36) was compared with published financial data from various sources (I-Net Bridge, company reports, etc.). Sixty-seven of 84 respondents correctly reported the return on asset (ROA) category. Fourteen cases exaggerated their ROA by one category and the remaining three cases diminished their ROA by one category.

Three Chi-square-based measures of association were calculated; i.e., the phi coefficient, the coefficient of contingency, and Cramer's V. Their respective values were 1.26, .63, and .78. All were significant at the .00000 level (rounded to the fifth decimal place), indicating a strong relation between the reported and actual ROA data. These factors point to an acceptably high degree of data reliability.

The fourth and final dimension for validity and reliability concerns construct validity. Construct validity is concerned with the question of what the research instrument is, in fact, measuring. Common factor analysis is one of the methods of analysing construct validity. The factor analysis found relatively high degrees of communality 
among the variables. Most of the dimension variables have communalities greater than 0.5 . The clear patterns of the factor loadings on the variables further validated the content and process constructs.

\section{Multiple Regression Analysis}

To ascertain the relative importance of the factors in explaining the variation in the dependent variables, multiple regression analysis was used to analyse the relationship between the dependent and independent variables. The objective of multiple regression analysis is to use the independent variables (two factors) whose values are known to predict the single dependent values (two performance factors). The Pearson r-correlations were calculated to find the strength and direction of the relationships between the factors and the performance archetypes. By using p-values, it was possible to distinguish between the levels of significance. It is apparent from Table 8 that the New Product Innovation factor has a significant positive effect on Input Performance $(\mathrm{p}<0.01)$.

Table 8: Correlation Matrix

\begin{tabular}{|c|c|c|c|c|c|}
\hline & & $\begin{array}{c}\text { New Product } \\
\text { Innovation }\end{array}$ & $\begin{array}{c}\text { Process } \\
\text { Innovation }\end{array}$ & $\begin{array}{c}\text { Input } \\
\text { Performance } \\
\end{array}$ & $\begin{array}{c}\text { Output } \\
\text { Performance }\end{array}$ \\
\hline New Product Innovation & $\begin{array}{c}\text { Pearson Correlation } \\
\text { Sig. (2-tailed) } \\
\text { N }\end{array}$ & $\begin{array}{c}1.000 \\
84\end{array}$ & $\begin{array}{c}.614^{*} \\
.000 \\
84\end{array}$ & $\begin{array}{c}.684^{*} \\
.000 \\
84\end{array}$ & $\begin{array}{c}.296^{*} \\
.000 \\
84\end{array}$ \\
\hline Process Innovation & $\begin{array}{c}\text { Pearson Correlation } \\
\text { Sig. (2-tailed) } \\
\text { N }\end{array}$ & $\begin{array}{c}.614 * \\
.000 \\
84\end{array}$ & $\begin{array}{c}1.000 \\
8 \\
84\end{array}$ & $\begin{array}{c}.467 * \\
.000 \\
84\end{array}$ & $\begin{array}{c}.175 \\
.111 \\
84\end{array}$ \\
\hline Input Performance & $\begin{array}{c}\text { Pearson Correlation } \\
\text { Sig. (2-tailed) } \\
\text { N }\end{array}$ & $\begin{array}{c}.684 * \\
.000 \\
84\end{array}$ & $\begin{array}{c}.467 * \\
.000 \\
84\end{array}$ & $\begin{array}{c}1.000 \\
84\end{array}$ & $\begin{array}{c}.435 * \\
.000 \\
84\end{array}$ \\
\hline Output Performance & $\begin{array}{c}\text { Pearson Correlation } \\
\text { Sig. (2-tailed) } \\
\text { N }\end{array}$ & $\begin{array}{c}.296 * \\
.006 \\
84\end{array}$ & $\begin{array}{c}.175 \\
.111 \\
84 \\
\end{array}$ & $\begin{array}{c}.435 * \\
.000 \\
84\end{array}$ & $\begin{array}{c}1.000 \\
84\end{array}$ \\
\hline
\end{tabular}

* Correlation is significant at the 0.01 level (2-tailed).

The level of relationship ( $\mathrm{R}^{2}$ or $\mathrm{Rsq}$ ) that can be detected reliably with the proposed regression analysis was calculated to indicate the percentage of total variation of the Input Performance factor (InP). The New Product Innovation factor $(\mathrm{Rsq}=0.4676)$ explains $47 \%$ of the total variation of the Input Performance factor. It implies that the aggressiveness of a company's new product development program, in relation to the product, marketing, and innovation activities, determines the variation of the company's contribution to sales, efficiency of innovation project management, impact of the innovations, and research and development expenditure. The Process Innovation factor $(\mathrm{Rsq}=0.2182)$ explains $22 \%$ of the total variation of the Input Performance factor. It signifies that the emphasis a company places on a stated and working strategy of process innovation, and the way it evaluates process innovation's performance relative to objectives, determines the variation of the company's contribution to sales, efficiency of innovation project management, impact of the innovations, and R\&D expenditure.

The level of relationship ( $\mathrm{R}^{2}$ or Rsq) that can be detected reliably with the proposed regression analysis was calculated for the creation of the Output Performance factor (OutP). The New Product Innovation factor $(\mathrm{Rsq}=$ 0.0874) explains $9 \%$ of the total variation of the Output Performance factor. It signifies that the aggressiveness of a company's new product development program, in relation to the product, marketing, and innovation activities, determines the variation of the company's contribution to R\&D activities (patents registered) and the company's efficiency in using its assets (return on assets). The Process Innovation factor (Rsq $=0.0307$ ) explains $3 \%$ of the total variation of the Output Performance factor. It signifies that the emphasis a company places on a stated and working strategy of process innovation, and the way it evaluates process innovation's performance relative to objectives, determines the variation of the company's contribution to R\&D activities (patents registered) and the company's efficiency in using its assets (return on assets).

\section{LIMITATIONS ON THE RESEARCH}

This study confines its focus to the effects of innovation policy on company performance. In so doing, a number of other factors which affect company performance are omitted; e.g., marketing strategy, financial structure, 
culture, human resources, etc. The study was also restricted to South African-listed companies in the Industrial Consumer sector on the Johannesburg Stock Exchange.

\section{RECOMMENDATIONS}

The New Product Innovation factor reflects the aggressiveness of a company's new product development program in relation to its innovation activities. This factor comprises product innovation, marketing innovation, and management innovation. The New Product Innovation factor explains 47 percent of the total variation of the Input Performance factor which means that a strong market orientation, marketing proficiency, and a clear product definition have all been found to be positively correlated with company performance. The New Product Innovation factor also explains nine percent of the total variation of the Output Performance factor. It signifies that the aggressiveness of a company's new product development program, in relation to the product, marketing, and innovation activities, determines the variation of the company's contribution to R\&D activities and the company's efficiency in using its assets.

The Process Innovation factor reflects the emphasis a company places on innovation in process technologies, skills, and techniques, organisational systems, and administrative procedures that are involved in transforming inputs into outputs. The Process Innovation factor explains 22 percent of the total variation of the Input Performance factor. It signifies that the emphasis a company places on a stated and working strategy of process innovation and the way it evaluates process innovation's performance, relative to objectives, determines the variation of the company's contribution to sales, efficiency of innovation project management, impact of the innovations, and R\&D expenditure. The Process Innovation factor also explains three percent of the total variation of the Output Performance factor. It signifies that the emphasis a company places on a stated and working strategy of process innovation, and the way it evaluates process innovation's performance relative to objectives, determines the variation of the company's contribution to R\&D activities and the company's efficiency in using its assets.

This research indicates that innovation policy plays a key role in the formulation and implementation of business strategies. It is recommended that companies use innovation proactively as a competitive weapon and a key-positioning factor and that these companies should accept technical risk, increasing the sophistication of innovation components utilised and the number of innovations in which the company maintains competence.

It was noted that innovation is a process with a number of distinctive features that have to be managed. This study acknowledges that innovation depends on inventions but that inventions need to be harnessed to commercial activities before they can contribute to the growth of a company. Collaboration between the R\&D function and the strategic management function is thus recommended to activate the innovation process by identifying new and/or different combinations of market technology factors, which will create the competitive advantage necessary for sustaining industry leadership.

\section{CONCLUSION}

Strategic management is inter alia a process of managing a company's relationship with the environment. A critical concern of this discipline is optimising returns to the company's stakeholders over the long term. This means sustaining performance by balancing strategic investments in innovation with short-term profitability.

The main purpose of this study was to investigate innovation strategies in widespread use in technology intensive industries and to explore their relationship to company performance. In essence, the following two research questions were addressed in this study.

1. What are the prevalent innovation strategy archetypes being employed by South African companies in technology intensive industries?

2. What relationships can be observed between the innovation strategy archetypes and company performance?

Question one was addressed through factor analysing the innovation strategy archetypes obtained from the survey. The second question was answered by regression analysis. The two distinct innovation strategy factors 
obtained with the analysis proved to positively influence the company performance archetypes and were classified as New Product Innovation and Process Innovation factors.

The present study makes a contribution to the field of strategic management research by integrating the archetypes of several previous studies to derive a more comprehensive taxonomy of innovation strategy archetypes. It also derives a broader set of archetypes for use in strategic management research. The results show that strategy choices can significantly affect company performance. It thereby indicates which of the underlying archetypes have the strongest relationship with company performance.

\section{AUTHOR INFORMATION}

Prof. Theuns Pelser is the Director and Strategy Professor of the Graduate School of Business and Government Leadership, North-West University, Mafikeng Campus. Prior to this appointment, he was Strategy Manager at Sasol, a petro-chemical multinational company. He holds a $\mathrm{PhD}$ in Strategic Management from Potchefstroom University. His research focuses on technology strategies, innovation strategies, and technology management processes and their relationship to company performance. E-mail: theuns.pelser@nwu.ac.za

\section{REFERENCES}

1. Anderson, J. C., Gerbing, D. W., \& Hunter, J. E. (1987). On the assessment of unidimensional measurement: Internal and external consistency and overall consistency criteria. Journal of Marketing Research, 24, 432-437.

2. Brush, C. G., \& Vanderwerf, P. A. (1992). A comparison of methods and sources for obtaining estimates of new venture performance. Journal of Business Venturing, 7(2), 157-170.

3. Clemens, C. (2006). Monopolistic competition and entrepreneurial risk-taking. Economics Letters, 93(1), 68-74.

4. Cooper, A. C. (1979). Strategic management: new ventures and small business. In D. E. Schendel \& C. W. Hofer (eds.), Strategic management: A new view of business policy and planning. Boston, MA: Little Brown.

5. Dahan, G., \& Shoham, A. (2014). Strategic orientations: Developing an integrative model of pioneering, entrepreneurial, and stakeholder orientations. Procedia - Social and Behavioral Sciences, 109, 758-762.

6. $\quad$ Ensminger, D. C., Surry, D. W., Porter, B. E., \& Wright, D. (2004). Factors contributing to the successful implementation of technology innovations. Educational Technology \& Society, 7(3), 61-72.

7. Freeman, C. (1994). The economics of technical change. Cambridge Journal of Economics, 18(5), 463514.

8. Garnett, A., \& Pelser, T. G. (2007). Organisational barriers to creativity in South African higher education institutions. South African Journal of Higher Education, 21(1), 50-67.

9. Hair, J. F. JNR, Black, W. C, Babin, B. J., \& Anderson, R. E. (2010). Multivariate data analysis: A global perspective ( $7^{\text {th }}$ ed.). Upper Saddle River: Pearson Prentice Hall.

10. Hansen, A. (2010). Nonfinancial performance measures, externalities and target setting: a comparative case study of resolutions through planning. Management Accounting Research, 21(1), 17-39.

11. Hamel, G., \& Prahalad, C. K. (2006). The core competence of the corporation strategic learning in a knowledge economy. In D. Hahn \& B. Taylor (eds.), Strategische unternehmungsplanung - strategische unternehmungsführung. Berlin, Heidelberg: Springer.

12. Harmon, P., \& Davenport, T. (2007). Business process change ( $2^{\text {nd }}$ ed.). Burlington, Massachusetts: Morgan Kaufmann.

13. Hung-Chia, S. H. (2013). Technology timing of IPOs and venture capital incubation. Journal of Corporate Finance, 19(1), 36-55.

14. Levitt, T. (1983). The globalisation of markets. Harvard Business Review, 61(3), 92-102.

15. Lussier, R. N. (1995). A non financial business success versus failure prediction model for young firms. Journal of Small Business Management, 33(1), 8-20.

16. Myers, S., \& Marquis, D. G. (1969). Successful industrial innovation: A study of factors underlying innovation in selected firms. (NSF 69-17.) Washington: National Science Foundation. 
17. Miller, D., \& Toulouse, J. M. (1986). Strategy, structure, CEO personality and performance in small firms. American Journal of Small Business, 10(3), 47-62.

18. Murphy, G. B., Trailer, J. M., \& Hill, R. C. (1996). Measuring performance in entrepreneurship research. Journal of Business Research, 36(1), 15-23.

19. Ohmae, K. (1989). Managing in a borderless world. Harvard Business Review, 67(3), 152-161.

20. Panagiotou, G. (2007). Reference theory: Strategic groups and competitive benchmarking. Management Decision, 45(10), 1595-1621.

21. Pandian, J. R, Thomas, H., Furrer, O., \& Bogner, W. C. (2006). Performance differences across strategic groups: an examination of financial market-based performance measures. Strategic Change, 15(6), 373383.

22. Parasuraman, A., Grewal, D., \& Krishnan, R. (2007). Marketing research (2nd ed.). Boston, MA: Houghton Mifflin Harcourt.

23. Pérez-Luño, A., \& Cambra, J. (2013). Listen to the market: do its complexity and signals make companies more innovative? Technovation, 33(6/7), 180-192.

24. Pérez-Luñoa, A., Wiklundb, J., \& Cabrera, R. A. (2011). The dual nature of innovative activity: How entrepreneurial orientation influences innovation generation and adoption. Journal of Business Venturing, 26(5) 555-571.

25. Pelser, T. G. (2001). A strategic management taxonomy of technology and innovation. (Unpublished PhD thesis). Potchefstroom: Potchefstroomse Universiteit vir Christelike Hoër Onderwys.

26. Porter, M. E. (1980). Competitive strategy: Techniques for analysing industries and competitors. New York: Free Press.

27. Porter, M. E. (1983). The technological dimension of competitive strategy. Research on Technological Innovation, Management and Policy, 1, 1-33.

28. Rauch, A., Wiklund, J., Freese, M., \& Lumpkin, T. (2009). Entrepreneurial orientation and business performance: Cumulative empirical evidence. Entrepreneurship Theory and Practice, 33(3), 761-779.

29. Rothwell, R. (1992). Successful industrial innovation: critical factors for the 1990s. R\&D Management, 22(3), 221-239.

30. Sapienza, H. J., Smith, K. G., \& Gannon, M. J. (1988). Using subjective evaluations of organizational performance in small business research. American Journal of Small Business, 12(3), 45-53.

31. Shin, J., \& Lee, H. (2013). Low-risk opportunity recognition from mature technologies for SMEs. Journal of Engineering and Technology Management, 30(4), 402-418.

32. Shoham, A., \& Fiegenbaum, A. (2002), Competitive determinants of organisational risk-taking attitude: the role of strategic reference points. Management Decision, 40(2), 127-141.

33. Song, M., Zhao, Y. L., \& Di Benedetto, C. A. (2013). Do perceived pioneering advantages lead to firstmover decisions? Journal of Business Research, 66(8), 1143-1152.

34. Trott, P. (1998). Innovation management and new product development. London: Financial Times.

35. Zahra, S. A., \& Covin, J. (1994). The financial implications of fit between innovation types and sources and competitive strategy. Journal of High Technology Management Research, 5(2), 183-212.

36. Zahra, S. A., \& Hayton, J. C. (2008). The effect of international venturing on firm performance: The moderating influence of absorptive capacity. Journal of Business Venturing, 23(2), 195-220.

37. Zien, K. A., \& Buckler, S. A. (1997). From experience, dreams to market: Crafting a culture of innovation. Journal of Product Innovation Management, 14(4), 274-287. 